\title{
The Effects of Politician's Moral Violations on Voters' Moral Emotions
}

\author{
Annemarie S. Walter ${ }^{1,2}\left[\right.$ (D) David P. Redlawsk ${ }^{3}$ (D)
}

Accepted: 22 August 2021

(c) The Author(s) 2021

\begin{abstract}
Existing empirical research on voters' responses to individual politicians' moral transgressions pays limited attention to moral emotions, although moral emotions are an integral part of voters' moral judgment. This study looks at U.S. voters' discrete moral emotional responses to politician's moral violations and examines how these discrete moral emotional responses are dependent on voters' own moral principles and the extent to which they identify with a political party. We report on a $5 \times 3$ between-subjects experiment where 2026 U.S. respondents reacted to politicians' violations of one of five moral foundations defined by Moral Foundations Theory. We randomly vary which moral foundation is violated and the partisanship of the politician. While voters' own moral principles somewhat condition moral emotional responses, we find that voters' moral emotional responses mostly depend on partisan identification. When voters share party identity with a politician committing a moral violation, they respond with less anger, contempt, disgust and shame than when they do not share party identity. The effect is greater among strong partisans. However, we find limited evidence that specific moral emotions are activated by violations of particular moral foundations, thereby challenging Moral Foundations Theory.
\end{abstract}

Keywords Moral emotions $\cdot$ Immoral behavior $\cdot$ Moral foundation theory $\cdot$ Political scandal $\cdot$ Partisanship

Annemarie S. Walter

Annemarie.Walter@nottingham.ac.uk

David P. Redlawsk

redlawsk@udel.edu

1 School of Politics and International Relations, University of Nottingham,

Nottingham NG7 2RD, UK

2 School of Governance, Law and Urban Development, Saxion University of Applied Sciences, 7417 DH Deventer, The Netherlands

3 Department of Political Science and International Relations, University of Delaware, 18 Amstel Avenue, Newark, DE 19716, USA 
In politics, moral transgressions by politicians often dominate the news when they become known. Yet, in the United States, such transgressions may be less consequential than ever, at least in some contexts. For many Americans, the confirmation of Brett Kavanaugh to the Supreme Court in spite of credible claims about prior behavior highlights this new reality. In contrast, not long before the Kavanaugh debate, Democratic Senator Al Franken was forced to step down in the face of sexual harassment allegations. More recently, newly elected Democratic Congresswoman Katie Hill resigned her office in the face of a sex scandal. Meanwhile, the man who appointed Justice Kavanaugh, Donald Trump, seemed particularly immune to the typical effects of moral transgressions, getting elected President despite his clear flaunting of moral standards, including his claim that he could shoot someone in the middle of New York City's 5th Avenue without consequences. In some sense, it might be right to say that in current American politics, everything seems consequential as partisan media pounce on the latest supposed transgression by the other side. Yet given the overarching presence of Trump and his continual flaunting of moral norms, at least until January 20, 2021, little else seemed consequential; in a sense, when everything is outrageous, nothing seems outrageous.

Typically and historically, moral transgressions that lead to political scandals have been documented to be associated with decreases in voters' evaluations of candidates and their trust in politicians, the political system, and politics in general (e.g. Bowler \& Karp, 2004; Doherty et al., 2011; Von Sikorski 2018; Vonnahme, 2014). At the same time, as recent events show, these effects are clearly not inevitable. In this paper we seek to explain why voters respond heterogeneously to moral transgressions. One interesting aspect of these initial examples is that they come from different sides of the partisan aisle, suggesting perhaps asymmetries in how partisan voters respond. ${ }^{1}$ In particular, the likelihood of expressing negative emotional responses that can lead to reduced support for transgressive politicians may be biased by partisan preferences, as is well established for evaluations in other contexts (Campbell et al., 1980; Redlawsk, 2002; Taber \& Lodge, 2006).

We argue that a better understanding of the emotions voters experience when confronted with politicians' purportedly immoral behavior can improve our understanding of their responses to moral transgressions. In particular, the activation, or not, of moral emotional responses may condition how voters perceive the violation at hand. Moral emotions (Haidt, 2003) are those that consider the interests of other people or of society, and are a subset of the full range of emotions humans can experience. Exposure to immoral behavior generally would be expected to evoke moral emotions. Thus immoral behavior by politicians, with its potential to impact those whom politicians are supposed to serve, should do so as well.

\footnotetext{
1 There are certainly examples of Republicans stepping down in the face of moral transgressions and Democrats remaining in office. Nonetheless, a brief review of recent years suggests there is an asymmetry in the effects of moral transgressions.
} 
But as Walter and Redlawsk (2019) find in examining valence emotion, the potential impact of immoral behavior by politicians is conditioned by partisanship. ${ }^{2}$ They view partisanship as a group identity (Mason, 2018), such that when an in-party politician violates moral imperatives, co-partisans do not have the negative emotional response one might anticipate. However, it may be that this finding is an artifact of their analytical approach. While Haidt (2003) defines a set of discrete moral emotions, Walter and Redlawsk (2019) examine only valence emotion-obscuring the effects of specific emotional responses. In this paper we extend this by considering a set of discrete moral emotions and examining how these moral emotional responses depend on voters' own moral principles and partisan group identity. Discrete emotional responses in politics have been shown to affect voter turnout, candidate evaluation, and attention to politics, among other things (Marcus et al., 2000; Redlawsk, 2006; Redlawsk \& Pierce, 2017). It is not unreasonable to think they would matter for moral transgressions.

Importantly, we examine voters' moral emotional responses to moral transgressions, but not to political scandals as such. Moral transgressions may be precursors to political scandals, which are "actions or events involving certain kinds of transgressions which become known to others and are sufficiently serious to elicit a public response" (Thompson, 2000, p. 13). Before a moral transgression can become a scandal, voters must see the action as transgressive, one indication of which is their moral emotional responses to the politician's action. Thus, given our focus, this paper can speak to what may lead to political scandal, but does not address what happens when scandals are brought to public attention by the media and other actors.

We consider three questions. First, which, if any, specific moral emotions are activated by politicians' moral transgressions? Second, do voters' personal commitments to moral principles condition moral emotional responses when that principle is violated? Third, what role does partisan identity play in conditioning discrete moral emotional responses to politicians' moral transgressions?

We find limited evidence that specific moral emotions are activated by violations of associated moral principles and mixed results for the influence of personal moral commitments. We do, however, find that voters' specific moral emotional responses depend on partisan identity and strength. Voters who share partisan identity with the politician committing a moral violation respond with less anger, contempt, disgust, and shame and with more pride, elevation, and sympathy than they do for an outgroup politician. We also find that strong partisans express a lower level of othercondemning and negative self-conscious moral emotions to in-party violations than do others.

\footnotetext{
2 This need not be due to motivated reasoning in the service of defending priors, but a more basic case of partisanship as identity creating a perceptual lens (Campbell et al., 1980) through which moral violations may be viewed. The distinction is important. Walter and Redlawsk (2019) do not examine motivated reasoning processes as such since their study used unnamed "politicians" for whom participants had no prior evaluations to maintain. Earlier work has also examined political preferences and moral principles, including Emler (2003), Emler et al. (1983), Narvaez et al. (1999) and Sparks and Durkin (1987) although from varying perspectives and not directly examining partisanship in the U.S. as we do here.
} 


\section{Moral Principles and Transgressions}

By "moral transgression," we mean observed behavior that violates people's intuitive sense of what is right and wrong. We use Moral Foundation Theory (MFT) to provide context for the moral evaluations we test (Graham et al., 2011; Haidt \& Joseph, 2004). According to MFT, moral judgments are an automatic intuitive process (Clifford et al., 2015) where people inherently know whether acts are right or wrong (Haidt, 2001). Thus, people can make swift judgments of the morality of an act. However, it is much harder to explain the judgement, since to do so requires developing a rationale to match the affective response (Haidt \& Hersh, 2001). Haidt and Hersh (2001) argue that intuitions and emotions most often precede and guide moral judgment, which accords with Zajonc's (1980) argument that "preferences need no inferences."

Limited attention has been paid to specific emotional responses to politicians' individual moral transgressions in "daily politics". ${ }^{3}$ Notable exceptions are Halmburger et al. (2012), Jiang et al. (2011) and Walter and Redlawsk (2019). Halmburger et al. (2012) examine people's moral emotional responses to exposure to a news report in which a fictitious politician is accused of abuse of public funds. Jiang et al. (2011) examines whether negative emotional responses to a scandalous person (non-politician) can be alleviated. More recently, Walter and Redlawsk (2019) examine emotions in response to violations of moral foundations, finding that negatively-valenced responses are tempered by the importance voters place on specific moral principles, and on the partisanship of the actor in question. While all three of these studies address emotions in general terms, none examines discrete moral emotions and only Walter and Redlawsk (2019) take partisanship into account while looking at responses to individual politicians.

\section{Moral Emotions}

Moral emotions are defined by Haidt (2003, p. 76) as those "that are linked to the interests or welfare either of society as a whole or at least of persons other than the judge or agent". He identifies moral emotions on the basis of two traits. First, a moral emotion is easily triggered by disinterested elicitors, i.e. situations that do not directly harm or benefit the self. Second, the emotion's action tendencies are prosocial, i.e. the disinterested event triggers an action that benefits others or the social order. Haidt (2003) does not present moral emotions as a binary concept; they differ in the degree to which they are triggered by disinterested elicitors and are prosocial. Emotions like anger can be moral in some contexts while not in others.

According to intergroup emotions theory (Smith \& Mackie, 2016) moral emotions are experienced at the individual level, and also on behalf of a social group

\footnotetext{
3 There is significantly more research on the role of moral emotions and moral transgressions in the context of war and intergroup conflict (e.g. Halperin \& Schori-Eyal, 2019; Imhoff et al., 2012; Iyer et al., 2007; Pagano \& Huo, 2007).
} 
with which one identifies. Group identity becomes part of an individual's self-identity (Smith \& Mackie, 2016) such that behavior of fellow group-members, history, and collective action of the group can evoke strong emotions (Lickel et al., 2011). Since group-based emotions are experienced in response to actions of fellow-group members, people's evaluation of an event is based on the implications of the event for the group as a whole, rather than solely the implications for the self. For instance people may experience the moral emotion anger when observing that some member of the group is treated unfairly.

Moral emotions are dependent on salient group memberships and moderated by the degree of identification with the group (Smith \& Mackie, 2016). Positive groupbased emotions are more strongly experienced by highly identified group members compared to less identified group members. The reverse is true for negative groupbased emotions, where highly identified group members are likely to avoid feeling negative emotions towards the in-group (Smith \& Mackie, 2016; Smith et al., 2007). Thus, group identification is likely to bias emotional response. Within the context of politics, and especially American politics in the first part of the twenty-first century, partisanship operates as a group identity (Mason, 2018) with powerful effects on how partisans perceive actions by politicians.

Haidt (2003) distinguishes four families of moral emotions, each of which includes a set of discrete emotions.

\section{Other Condemning Emotions}

These are identified by negative feelings about the character or actions of others, and principally consist of anger, contempt, and disgust. Anger asks for restoration of the moral order and as a moral emotion is elicited by a perceived unjustified insult or unfair treatment of the group, often accompanied with the desire to correct this unfairness. Anger that results from witnessing a person or group commit a moral violation that harms another group or person, but which does not affect the self is referred to as outrage (Rothschild et al., 2013). Disgust is a feeling of revulsion elicited by a physical object or social violation and motivates avoiding the elicitor and expelling or breaking off contact with the offending entity, often coupled to a motivation to wash or purify oneself. Disgust has a prosocial action tendency as it sets up a reward and punishment system for those who involve in culturally inappropriate behavior, as these members of society are ostracized (Haidt, 2003). Contempt falls between disgust and anger, with elements of both, involving looking down upon someone and feeling morally superior. Feelings of contempt do not cause people to disassociate or to attack like anger and disgust do; contempt leads to treating the other with less warmth and respect and may weaken the experience of other moral emotions (Haidt, 2003). ${ }^{4}$

\footnotetext{
${ }^{4}$ Political psychologists generally focus on a small set of emotions that are seen as potentially motivating political behavior, anxiety, enthusiasm, and anger (as motivational, not moral). While other emotions have been studied, such studies have not explicitly engaged moral emotions.
} 


\section{Self-Conscious Emotions}

This family deals with feelings of oneself in relationship to others, such as shame, guilt, pride, and embarrassment (Haidt, 2003; Tangney et al., 2007). Shame may be elicited committing a moral violation and knowing that someone else knows about it, making one want to deny, hide, or disappear (Haidt, 2003; Tangney et al., 2007). Group-based shame, i.e. feelings of shame experienced in response to the transgressions and failures of fellow group members, is elicited by threats to group-image and concerns about maintaining or repairing positive group image (Lickel et al., 2011; Tangney et al., 2007). The difference between group-based shame and the strongly related moral emotion guilt is that shame is felt when fellow group members' wrongdoing reflects badly on one's self-image; guilt is evoked when one feels personally or collectively complicit. Shame leads to denial or distancing oneself from the shame inducing event, group member, or group identity; guilt motivates to correct the wrongdoing (Lickel et al., 2011). Avoiding feelings of shame can make people blind to moral violations of the group. The opposite of shame is the positive emotion of pride (Haidt, 2003), an emotion that rewards morally correct choices and behavior and is considered important as a motivator of conforming to moral standards (Tangney et al., 2007). Group pride can lead to stronger identification with the group (Smith et al., 2007).

\section{Other Suffering Emotions}

These entail emotions that address suffering of others, such as sympathy and compassion. Sympathy is elicited by the perception of suffering; it does not necessitate direct experience of the other's feelings (Eisenberg, 1986). Sympathy results in altruistic helping behavior (Tangney et al., 2007).

\section{Other Praising Emotions}

The final family comprises positive moral emotions, such as elevation and gratitude, that people experience when confronted with manifestations of admirable behavior of others, such as kindness, loyalty, generosity and self-sacrifice (Haidt, 2003). Elevation inspires people to better themselves and do these kinds of acts (Algoe \& Haidt, 2009; Haidt, 2003). Thus, elevation is the opposite of disgust. Politicians are expected to act as moral exemplars and have the potential to inspire citizens by their behavior.

\section{Moral Foundations and Emotional Response}

MFT categorizes moral intuitions into five core foundations: care; fairness; loyalty; authority; and sanctity (Haidt \& Graham, 2011). Care refers to the dislike for the suffering of others, while fairness is a commitment to fairness and justice. These two 
foundations are individualizing, as they focus on individuals. The remaining three are binding foundations (Graham et al., 2011), supporting the group. Loyalty is a commitment to one's own group. Authority refers to respect for authority and tradition, and sanctity refers to concerns with purity and contamination. MFT is meant to cover the full range of moral concerns, including those found in non-Western cultures, in religious practices, and among political conservatives (Graham et al., 2011). People differ in the extent to which they endorse these five moral foundations and thus MFT also provides for moral diversity (Graham et al., 2011). MFT sees these five foundations as innate and "organized in advance of experience" (Haidt \& Joseph, 2011).

However, the existence of five distinct moral foundations underlying moral judgment is contested (Iurino \& Saucier, 2020; Schein \& Gray, 2018); for instance, proponents of the theory of Dyadic Morality argue that these moral concerns largely overlap and are all tied to intuitive perceptions of harm (Schein \& Gray, 2018). Other scholars challenge the innateness of moral foundations (Ciuk, 2018; Hatemi, et al., 2019; Smith et al., 2017; Suhler \& Churchland, 2012), arguing that moral foundations are not stable dispositional traits, that little evidence exists that moral foundations are heritable, and the proposed causal arrow from moral foundation to political ideology is not supported. Further, Walter and Redlawsk (2019) find that partisan identity more strongly conditions the expression of negatively-valenced emotion when politicians violate moral expectations, than do people's personal commitments to specific moral foundations. Notwithstanding these growing challenges to MFT, it remains a prominent theory in the field and provides a context to organize tests of moral transgressions.

Using MFT as we do here provides an additional opportunity to test some of its assumptions. But more importantly for our purposes, the five moral foundations are argued to be connected to specific emotions which are triggered when a related moral foundation is violated (Haidt \& Joseph, 2004; Rozin \& Lowery, 1999). Care violations are thought to elicit compassion, fairness violations should elicit anger and guilt, authority violations should elicit fear, contempt and resentment, loyalty violations should elicit rage, and sanctity violations should elicit disgust (Haidt, 2003; Haidt \& Joseph, 2004). ${ }^{5}$ While MFT does not argue that the links between these moral emotions and moral foundations are exclusive (Landmann \& Hess, 2017), any given moral emotion should be elicited more intensely by violation of the associated moral foundation compared to other moral emotions. In one study, Landmann and Hess (2017) question this connection, finding that only disgust is elicited more by sanctity violations than other violations, and finding no differences among other moral emotions. Here we intend to more fully examine this supposed link.

Considering the important role that moral emotions are thought to play in moral judgment, it is remarkable how little research attention they have received in the examination of individual politician's moral transgressions. In examining this, we focus on a specific set of the other-condemning (anger, contempt, disgust),

\footnotetext{
5 Non-violation of fairness elicits the emotion gratitude, non-violation of loyalty elicits group pride and belongingness and non-violation of authority elicits respect or awe (Haidt \& Joseph, 2004).
} 
self-conscious (shame, pride), other-suffering (sympathy) and other-praising emotions (elevation) and the extent to which they are triggered when confronted by moral transgressions by politicians.

\section{Hypotheses}

Given this review of the literature on moral emotions and moral foundations, we formulate the following hypotheses testing the effects of violations of moral principles on specific moral emotions, including the conditional effects that may arise from the influence of both one's own moral values and partisan identity on perceptions of same and other-party actors. If, as adherents to MFT argue, these moral intuitions are innate and foundational, conditional effects of one's own moral principles should be strong, while the effects of partisan identity should be more limited. If, however, we find limited moral principles effects and stronger partisan effects, we will add to the evidence challenging the foundational nature of MFT.

\section{Moral Foundation Hypothesis (H1)}

MFT argues that specific moral emotions are related to the individual foundations. This leads us to expect that the violation of a given foundation by a politician will elicit a stronger negative response in its related moral emotions. Thus, Hypothesis 1: Specific moral emotions are elicited more intensely by violation of the related moral foundation than by violations of other moral foundations.

\section{Moral Commitment Hypothesis (H2)}

If moral foundations are core to people's moral principles, and particular moral emotions are related to those foundations, we would anticipate that the commitment to a given foundation and its incorporation into one's sense of right and wrong would be related to moral emotional responses to its violation. This leads to Hypothesis 2: The more strongly a particular moral foundation is endorsed, the more intensely the related moral emotion is experienced when a politician violates that particular foundation.

\section{Partisan Identity Hypothesis (H3)}

Partisan identity acts as a group identity, providing partisans with both an in-group and an out-group as they consider political actions. Accordingly, partisans are unlikely to be neutral in assessing moral violations by politicians of either their own party or a competing party. This response may vary by the particular moral emotion triggered by violation of a moral foundation. Thus, we have Hypothesis 3: Violations by an out-party politician will result in stronger feelings of other-condemning emotions, and weaker feelings of otherpraising emotions compared to an in-party violator. However, because self-conscious emotions (shame) relate to the negative actions of one's own group members, greater shame should be felt in response to an in-party violation than an out-party violation. 


\section{Party Identification Strength Hypothesis (H4)}

If partisanship determines responses to partisan actors violating moral foundations (H3), we would then further expect that the strength of partisan identity would condition the nature of that response. As in other domains, stronger partisans may respond differently than those holding only a weak partisan identity. This leads to Hypothesis 4: Strong partisans will express greater feelings of self-conscious emotions and weaker feelings of other-condemning emotions in response to in-party violations compared to those who identify less strongly with their party.

\section{Method}

We conducted a between-subjects experiment in a 5 (five moral foundations) $\times 3$ (politician's party-Republican, Democrat, no partisanship) design with vignettes embedded in a survey of 2026 U.S. voters. Each participant was randomly assigned a pre-tested vignette describing a fictional, but realistic sounding, scenario in which a [Democrat, Republican, no party] politician's behavior violated a moral foundation.

Vignettes were drawn from a pre-test of 25 vignettes with 648 U.S. respondents on Amazon Mechanical Turk. This set of vignettes builds on Clifford et al. (2015) standardized vignettes, which we modified to ensure a political context. Five vignettes were tested for each moral foundation. We selected the vignettes that best represented each moral foundation while also being perceived by participants as understandable and realistic. See the Online Supplementary Materials (OSM) for details of the conditions and the pre-test.

The main experiment was conducted online using Qualtrics software between 11 and 20 August, 2017. Respondents were recruited through Survey Sampling International (now known as Dynata). The sample successfully matched the adult population of the United States on age, gender, race/ethnicity, income, and region of residence. (See OSM Table A2.3.)

Each participant viewed a single vignette to eliminate spillover effects from viewing multiple foundations. After exposure to the vignette, participants reported the extent they experienced feelings of anger, pride, shame, disgust, contempt, sympathy, optimism about humanity, warm-heartedness, and uplift toward the politician described in the vignette. The order of the emotions was randomized. Finally, we gathered sociodemographics and information on respondents' own moral values and partisanship (see OSM for full survey).

\section{Analytical Design and Operationalization}

We exclude respondents with missing values on any of the dependent or independent variables included in our analyses, leaving 1918 cases for analysis. Randomization checks confirm that conditions remained balanced on pre-treatment covariates even after these cases were removed (OSM Table A2.4). 
Emotional responses were measured following exposure to the moral violation vignette, prompted by the question: "When you think about this politician's behavior, how does it make you feel?" Respondents reported their levels of contempt, anger, disgust, shame, pride, sympathy and elevation. As there is no widely known English word for elevation (Algoe \& Haidt, 2009), we use three of Schnall et al. (2010) indicators: feeling warm-hearted, optimistic about humanity, and uplifted. All emotions are measured on a five-point scale, where $0=$ not at all, and $4=$ extremely. Dependent variables are ordinal and thus we estimate ordered probit regression models.

To assess participants' own moral values we use the most prominent instrument, Graham et al.'s (2011) 30-item Moral Foundations Questionnaire, which measures endorsement of each of the five intuitive systems posited by MFT (See OSM for MFQ details). The subscales for the five specific moral foundations are measured by 6 items each, where scores run between 0 and 5 . The Cronbach alpha's of the subscales care, fairness, loyalty, authority, sanctity are respectively, $0.72,0.68,0.72,0.69$ and 0.79 .

Partisanship is measured using a typical 7-point scale, constructed from a series of questions that first ask whether the respondent is a Democrat, Republican, or Independent, and then ask the strength of party preference. Independents were asked whether they leaned toward one party. Strength of party identification is a folded measure using both questions, where strong partisan $=1$, weak parti$\operatorname{san}=2$, and leaning partisan $=3$, with non-leaning independents dropped for the party strength analysis.

\section{Results}

\section{Hypothesis 1: Moral Foundations}

Table 1 shows how respondents reported experiencing moral emotions when exposed to different moral violations. Of particular note is that anger, disgust, and shame are the top three emotions generated across all five foundations, although their order varies. Violation of the care foundation generates the strongest responses for all of the negative moral emotions, compared to other foundations, as well as one of the positive moral emotions (sympathy). While respondents clearly reported different levels of emotional response across the vignettes, Table 1 leads us to question whether there is the expected connection between the violation of a particular foundation and specific emotional response.

However, we face difficulty in making this assessment based solely on the analysis in Table 1. Given that each vignette tests a different foundation, we cannot know whether it is the strength of the emotional response elicited by a given moral foundation violation, or the fact that a particular moral transgression is perceived as more important by a given participant that is driving our results. Moral transgressions differ not only in which moral foundation they violate, but also 
Table 1 Percentage of respondents reporting feeling specific moral emotions in response to exposure to one of the moral violations

\begin{tabular}{llllll}
\hline & Care & Fairness & Loyalty & Authority & Sanctity \\
\hline Anger & 56.28 & 35.69 & 40.43 & 23.95 & 28.18 \\
Disgust & 67.02 & 42.25 & 45.52 & 28.44 & 38.48 \\
Contempt & 32.46 & 23.10 & 22.76 & 14.07 & 17.40 \\
Shame & 52.62 & 30.18 & 36.56 & 24.25 & 27.70 \\
Pride & 8.90 & 11.81 & 6.54 & 10.17 & 4.41 \\
Elevation & 4.45 & 8.14 & 2.18 & 4.79 & 3.19 \\
Sympathy & 23.82 & 10.24 & 6.30 & 11.38 & 8.58 \\
N & 382 & 381 & 413 & 334 & 408 \\
\hline
\end{tabular}

$\mathrm{N}=1918$. The table presents the percentage of people that reported to experience the specific emotion quite a bit (3) or extremely (4)

in perceptions of severity. ${ }^{6}$ To address this we use what we term the "meaning components" encapsulated into each vignette, which recognize that there is variance in assessing which foundation is violated by a vignette and in the power of a vignette to generate a response.

For each vignette, meaning components are constructed by combining two measures: (1) the aggregate perceptions of pre-test participants of which moral foundations are violated by the vignette, and (2) each main study respondent's perception of the severity of the vignette's moral transgression. In the pre-test, participants were asked to identify which moral foundation was violated by each vignette they viewed. Participants could either identify one of the five moral foundations, or indicate they did not think the violation violated any foundation. The distribution of responses (expressed in proportions) in the pre-test is used to identify the (moral) meaning components contained within each vignette (See OSM Table A1.1).

During the main study we asked respondents to indicate the severity of the moral violation presented in their assigned vignette on a 5-point scale, with 1 indicating not at all wrong and 5 extremely wrong (See OSM Table A2.2 for vignette severity ratings). Combining these two measures, we constructed six new independent variables for each vignette, measuring the relative weights of the vignette's meaning components by multiplying the proportion identifying each foundation as violated by each individuals' perception of severity. ${ }^{7}$

Given that there is variance in perceptions of the foundations violated by each vignette, and variance in severity, the direct links between vignette violation and emotional responses may be attenuated. To assess whether this is the case, we ran

\footnotetext{
${ }^{6}$ By design, our stimuli did not include a non-moral transgression vignette that could have been used as a comparison to the moral violations. Therefore, we cannot easily compare across foundations models as the baseline category will be different for each one. Our discussion here and below is not intended to compare foundations to each other, but to examine effects within each foundation.

7 To illustrate, we use an example for a respondent exposed to the fairness vignette and rating its severity as 4 on the 5-point scale. Pre-test participants perceived the vignette as follows: $2.4 \%$ thought the moral foundation Care was violated, $84.5 \%$ Fairness, 3.6\% Loyalty, 2.4\% Authority, and $2.8 \%$ Sanctity, with $4.4 \%$ saying no moral violation took place. Thus, the respondent rating its severity at 4 would receive the following meaning component scores: Care $0.024 \times 4=0.096$, Fairness $0.845 \times 4=3.38$, Loyalty $0.036 \times 4=0.144$, Authority $0.024 \times 4=0.096$, and Sanctity $0.042 \times 4=0.168$.
} 
Table 2 Voters' moral emotional responses to exposure to the meaning components in the vignettes

\begin{tabular}{|c|c|c|c|c|c|c|c|}
\hline & Anger & Disgust & Contempt & Shame & Pride & Elevation & Sympathy \\
\hline Care component & $\begin{array}{l}0.846 * * \\
(0.032)\end{array}$ & $\begin{array}{l}0.907 * * \\
(0.034)\end{array}$ & $\begin{array}{l}0.493 * * \\
(0.030)\end{array}$ & $\begin{array}{l}0.694 * * \\
(0.032)\end{array}$ & $\begin{array}{l}-0.292 * * \\
(0.037)\end{array}$ & $\begin{array}{l}-0.507 * * \\
(0.034)\end{array}$ & $\begin{array}{l}-0.108^{* *} \\
(0.031)\end{array}$ \\
\hline $\begin{array}{l}\text { Fairness compo- } \\
\text { nent }\end{array}$ & $\begin{array}{l}0.701 * * \\
(0.032)\end{array}$ & $\begin{array}{l}0.748 * * \\
(0.032)\end{array}$ & $\begin{array}{l}0.439 * * \\
(0.030)\end{array}$ & $\begin{array}{l}0.541 * * \\
(0.311)\end{array}$ & $\begin{array}{l}-0.227 * * \\
(0.035)\end{array}$ & $\begin{array}{l}-0.389 * * \\
(0.032)\end{array}$ & $\begin{array}{l}-0.319 * * \\
(0.033)\end{array}$ \\
\hline Loyalty component & $\begin{array}{l}0.778 * * \\
(0.051)\end{array}$ & $\begin{array}{l}0.830 * * \\
(0.052)\end{array}$ & $\begin{array}{l}0.432 * * \\
(0.048)\end{array}$ & $\begin{array}{l}0.611 * * \\
(0.050)\end{array}$ & $\begin{array}{l}-0.294 * * \\
(0.060)\end{array}$ & $\begin{array}{l}-0.607 * * \\
(0.057)\end{array}$ & $\begin{array}{l}-0.646^{* *} \\
(0.055)\end{array}$ \\
\hline $\begin{array}{l}\text { Authority compo- } \\
\text { nent }\end{array}$ & $\begin{array}{l}0.560 * * \\
(0.062)\end{array}$ & $\begin{array}{l}0.615^{* * *} \\
(0.063)\end{array}$ & $\begin{array}{l}0.371 * * \\
(0.062)\end{array}$ & $\begin{array}{l}0.527 * * \\
(0.063)\end{array}$ & $\begin{array}{l}-0.231 * * \\
(0.074)\end{array}$ & $\begin{array}{l}-0.355^{* * *} \\
(0.069)\end{array}$ & $\begin{array}{l}-0.048 \\
(0.069)\end{array}$ \\
\hline $\begin{array}{l}\text { Sanctity compo- } \\
\text { nent }\end{array}$ & $\begin{array}{l}-0.242^{* *} \\
(0.088)\end{array}$ & $\begin{array}{l}-0.020 \\
(0.090)\end{array}$ & $\begin{array}{l}-0.131 \\
(0.088)\end{array}$ & $\begin{array}{l}-0.117 \\
(0.089)\end{array}$ & $\begin{array}{l}-0.601 * * \\
(0.123)\end{array}$ & $\begin{array}{l}-0.423^{* *} \\
(0.109)\end{array}$ & $\begin{array}{l}0.080 \\
(0.103)\end{array}$ \\
\hline Republican & $\begin{array}{l}0.052 \\
(0.078)\end{array}$ & $\begin{array}{l}0.051 \\
(0.078)\end{array}$ & $\begin{array}{l}0.091 \\
(0.077)\end{array}$ & $\begin{array}{l}0.144 \\
(0.078)\end{array}$ & $\begin{array}{l}0.096 \\
(0.095)\end{array}$ & $\begin{array}{l}0.135 \\
(0.086)\end{array}$ & $\begin{array}{l}0.202 * * \\
(0.085)\end{array}$ \\
\hline Democrat & $\begin{array}{l}0.170 * \\
(0.072)\end{array}$ & $\begin{array}{l}0.066 \\
(0.073)\end{array}$ & $\begin{array}{l}0.181 * * \\
(0.072)\end{array}$ & $\begin{array}{l}0.208 * * \\
(0.073)\end{array}$ & $\begin{array}{l}0.069 \\
(0.089)\end{array}$ & $\begin{array}{l}0.128 \\
(0.080)\end{array}$ & $\begin{array}{l}0.223^{* *} * \\
(0.079)\end{array}$ \\
\hline Adjusted $\mathrm{R}^{2}$ & 0.151 & 0.167 & 0.069 & 0.109 & 0.105 & 0.101 & 0.070 \\
\hline
\end{tabular}

$\mathrm{N}=1918$ Table displays unstandardized regression coefficients with standard errors between parentheses $* \mathrm{p}<.05 * * \mathrm{p}<.01$. Model: Ordered Probit Regression See for full model OMS Table A1.3

the models partially displayed in Table 2 using the meaning components to predict moral emotions (See OSM Table A1.3 for full models). Even with this careful specification, we find only limited support for $\mathrm{H} 1$ : that violations of specific moral foundations lead to specific moral emotional responses.

There is no clear connection between particular moral violations and other suffering and other praising emotions. One possible reason may have to do with how we asked our questions. We focused respondents on the politician-violator more than the victim (if any). We would expect increasing positive moral emotions to be more likely to be in response to the victim rather than the perpetrator. For example, violations of care should elicit the emotion compassion for the victim, but not for the violator. Instead, we find only a small negative effect of the care component on sympathy. Other components such as fairness and loyalty seem to evoke a larger decrease in sympathy than care does, which is not what we expect.

The disconnect is not just with other praising and other suffering emotions. Anger focused on the politician should be elicited by violations of fairness. We find this effect for the fairness component, however care and loyalty violations also result in strong feelings of anger. Authority violations should elicit contempt. We find a moderate relationship here, yet stronger effects on contempt were found for the care, fairness, and loyalty components. Loyalty violations should elicit rage, which we did not measure, but for which anger should stand in. We do find a strong relationship between the loyalty component and anger. But we surprisingly find no significant relationship between the sanctity component and feelings of disgust. Our lack of clear support for $\mathrm{H} 1$ is not completely anomalous. It is in line with Landmann and Hess (2017), and supportive of their claim that links between particular emotions and specific moral foundations are not consistent. 
Table 3 Voters' moral emotional responses to politicians moral transgressions of different moral foundations that are dependent on voters' moral commitments

\begin{tabular}{|c|c|c|c|c|c|c|c|}
\hline & Anger & Disgust & Contempt & Shame & Pride & Elevation & Sympathy \\
\hline Vignette care $\times$ Foundation care & $\mathrm{X}$ & $\mathrm{X}$ & & $\mathrm{X}$ & & & \\
\hline \multicolumn{8}{|l|}{$\begin{array}{l}\text { Vignette fairness } \times \text { Foundation } \\
\text { fairness }\end{array}$} \\
\hline \multicolumn{8}{|l|}{$\begin{array}{l}\text { Vignette loyalty } \times \text { Foundation } \\
\text { loyalty }\end{array}$} \\
\hline $\begin{array}{l}\text { Vignette authority } \times \text { Foundation } \\
\text { authority }\end{array}$ & & & & $\mathrm{X}$ & & & \\
\hline $\begin{array}{l}\text { Vignette sanctity } \times \text { Foundation } \\
\text { sanctity }\end{array}$ & $\mathrm{X}$ & $\mathrm{X}$ & $X$ & $\mathrm{X}$ & & & $\mathrm{X}$ \\
\hline
\end{tabular}

$\mathrm{X}$ indicates that voters 'moral emotional responses to politicians' moral violations is dependent on voters' endorsement of the moral foundation that the politician violates (significant interaction effects). This table is based on the ordered probit models displayed in OSM Table A1.4

While we did not hypothesize partisan differences here, we do find Democrats are more likely than Republicans to express higher levels of the other condemning emotions of anger, contempt, and shame, while not differing on other praising and other suffering emotions of pride, elevation, and sympathy (or the other condemning emotion of disgust). While, as we will show below, there are strong partisan in- and outparty effects on moral emotional response, when averaging across vignettes there also appears to be differing levels of moral emotions expressed across the two sets of partisans, independent of the partisanship of the transgressing politician.

\section{Hypotheses 2: Moral Commitment}

Turning to $\mathrm{H} 2$, the Moral Commitment Hypothesis suggests that a stronger commitment to a particular moral foundation should result in stronger moral emotional responses to violation of that foundation. Table 3 summarizes the full model reported in OSM Table A1.4, showing the moral emotions voters experience when confronted with politicians' moral violations, and the extent to which responses are dependent on voters' own commitments to the moral foundations. We find mixed results across the types of moral emotions. We do not find any effect of own moral commitments on how voters respond in terms of the other-praising moral emotion elevation. For the other-suffering moral emotion sympathy, we only find an effect for sanctity. Voters who strongly endorse the moral principle of sanctity respond with less sympathy toward the politician violating it than voters that do not or only weakly endorse sanctity.

For the self-conscious emotions, own moral commitments do not matter for how voters respond to moral violations in terms of pride, but they do for shame. Voters who are strongly committed to the moral foundations of care, authority, and sanctity express higher levels of shame when these foundations are violated than voters with less commitment to them. 
We find a stronger connection between moral values commitment and foundation violation for the other-condemning emotions of anger, disgust, and contempt. Anger and disgust are both elevated by a stronger commitment to the moral value of care and the violation of its foundation by a politician. A stronger commitment to sanctity increases the strength of both of these emotions as well as contempt, when a politician violates the sanctity foundation.

As with the previous analysis, the results summarized in Table 3 may be partially explained by our focus on moral emotional responses to the politician violating the foundation, rather than the apparent victim of such violation. A "politician" is always the actor. The apparent victim, however, differs between the members of the general public (fairness, loyalty), another politician or party leader (care, authority), or no specific victim (sanctity). We would not expect voters to evidence greater positive moral emotions (other praising, other-suffering) for a politician violating moral foundations, which could account for few effects for elevation, sympathy, and pride (a self-conscious emotion). In fact, violation of the sanctity foundation decreases sympathy among those with more commitment to this value, as we would expect given the particular violation we used (homosexual relationship) and the focus on emotion toward the transgressing politician.

For the other condemning emotions of shame, anger, disgust, and contempt, we see consistent effects where the strength of certain moral values (care, authority, and sanctity) interact with violations of those foundations to increase the expression of these moral emotions. These results are in line with Hypothesis 2.

\section{Hypothesis 3: Group Identity}

Hypothesis 3, the Group Identity Hypothesis, suggests a partisan response to the violation of moral foundations. Walter and Redlawsk (2019) previously found this effect when examining negative emotions in aggregate, but we extend this work through examining discrete specific moral emotions. We expect to see an interaction between the partisanship of the politician violating a moral foundation and the party identification of the voter, where partisans will be less negative about their own party on the emotions of shame, anger, disgust, and contempt, and more positive on elevation, sympathy, and pride. Table 4 displays the results of this analysis (full models in OSM Table A1.5). To simplify interpretation, we construct a variable referencing the combination of vignette and respondent partisanship. This variable, labeled In-Party, is coded 1 when respondents and vignettes share partisanship and 0 when they do not.

An analysis averaged across all five foundations shows, as expected, respondents react differently when they share partisanship with the transgressing politician than when they do not, judging transgressors in their own group more leniently. Partisans respond with less anger, disgust, contempt, and shame, and with more pride, elevation and sympathy to in-party politicians committing a moral transgression. All results match the expectations of the group identity hypothesis except shame. Unexpectedly, voters respond with less shame when an in-party politician commits a moral transgression than they do when the violator is an 
Table 4 Voters' moral emotional responses to politicians' moral transgressions by shared partisanship

\begin{tabular}{|c|c|c|c|c|c|c|c|}
\hline & Anger & Disgust & Contempt & Shame & Pride & Elevation & Sympathy \\
\hline In-Party & $\begin{array}{l}-0.274 * * \\
(0.054)\end{array}$ & $\begin{array}{l}-0.265^{* *} \\
(0.054)\end{array}$ & $\begin{array}{l}-0.216^{* *} \\
(0.054)\end{array}$ & $\begin{array}{l}-0.199 * * \\
(0.054)\end{array}$ & $\begin{array}{l}0.238 * * \\
(0.065)\end{array}$ & $\begin{array}{l}0.190 * * \\
(0.058)\end{array}$ & $\begin{array}{l}0.120^{* * *} \\
(0.058)\end{array}$ \\
\hline $\begin{array}{l}\text { Vignette Repub- } \\
\text { lican }\end{array}$ & $\begin{array}{l}0.090 \\
(0.059)\end{array}$ & $\begin{array}{l}0.030 \\
(0.060)\end{array}$ & $\begin{array}{l}0.049 \\
(0.060)\end{array}$ & $\begin{array}{l}0.099 \\
(0.060)\end{array}$ & $\begin{array}{l}-0.001 * * \\
(0.073)\end{array}$ & $\begin{array}{l}0.099 \\
(0.066)\end{array}$ & $\begin{array}{l}0.006 \\
(0.065)\end{array}$ \\
\hline $\begin{array}{l}\text { Vignette Demo- } \\
\text { crat }\end{array}$ & $\begin{array}{l}0.111 \\
(0.062)\end{array}$ & $\begin{array}{l}0.092 \\
(0.062)\end{array}$ & $\begin{array}{l}0.108 \\
(0.063)\end{array}$ & $\begin{array}{l}0.214 * * \\
(0.063)\end{array}$ & $\begin{array}{l}-0.060 \\
(0.077)\end{array}$ & $\begin{array}{l}0.044 \\
(0.069)\end{array}$ & $\begin{array}{l}0.038 \\
(0.068)\end{array}$ \\
\hline Republican & $\begin{array}{l}0.106 \\
(0.072)\end{array}$ & $\begin{array}{l}0.095 \\
(0.072)\end{array}$ & $\begin{array}{l}0.147 * \\
(0.073)\end{array}$ & $\begin{array}{l}0.181 * \\
(0.073)\end{array}$ & $\begin{array}{l}0.253 \\
(0.090)\end{array}$ & $\begin{array}{l}0.253 * * \\
(0.080)\end{array}$ & $\begin{array}{l}0.293 * * \\
(0.080)\end{array}$ \\
\hline Democrat & $\begin{array}{l}0.167^{*} \\
(0.068)\end{array}$ & $\begin{array}{l}0.080 \\
(0.068)\end{array}$ & $\begin{array}{l}0.208 * * \\
(0.069)\end{array}$ & $\begin{array}{l}0.210 * * \\
(0.069)\end{array}$ & $\begin{array}{l}0.080 \\
(0.085)\end{array}$ & $\begin{array}{l}0.108 \\
(0.076)\end{array}$ & $\begin{array}{l}0.241 * * \\
(0.076)\end{array}$ \\
\hline Adjusted $\mathrm{R}^{2}$ & 0.008 & 0.008 & 0.039 & 0.023 & 0.128 & 0.025 & 0.056 \\
\hline
\end{tabular}

$\mathrm{N}=1914 *$ significant at level $0.05 * *$ significant at level 0.01. Model: Ordered Probit Regression The variable In-Party takes the value of 1 if the partisanship of the politicians displayed in the vignettes and the partisanship of the respondent are the same and In-Party takes a values of 0 if that is not the case. Table displays regression coefficients with standard errors in parentheses. Exposure to the non-partisan vignette is the baseline category. See for full models OSM Table A1.5

out-party politician. Perhaps the moral transgressions we used were not strong enough to threaten the group image. In that case, we would not expect any difference in response for in- versus out-group politicians. Alternatively, as suggested earlier, group members may become blind to moral violations, and thus fail to experience shame. Perhaps party adherents choose to turn a blind eye to moral transgressions to avoid experiencing shame.

To better understand these results, we calculated the mean predicted probabilities of each response level for each moral emotion, summarizing across all of the moral foundations. These are charted in Figs. 1 (positive moral emotions) and 2 (negative moral emotions.) Taking all negative moral emotions as a group (Fig. 1), it is quite clear that partisanship plays a significant role in reducing negative responses for an in-party politician who violates a moral foundation compared to an out-party violator. The effects are mostly visible at the extremes. For example, the mean predicted probability of expressing no anger at all to a moral violation is about $22 \%$ if an out-party politician is the actor, increasing to over $30 \%$ for an in-party actor. Likewise, the chance of feeling extremely angry at an out-party violator is about $21 \%$, while it is only $14 \%$ for the in-party politician. Similar results are evident for disgust, contempt, and shame. Unsurprisingly, levels of other-praising moral emotions are quite low, with the large majority of respondents predicted to express none of these (Fig. 2). Differences between inand out-party actors are much less visible, but especially for elevation and pride, when viewing an out-party actor respondents are more likely to say they do not feel any positive emotion at all than when viewing an actor of their own party. 


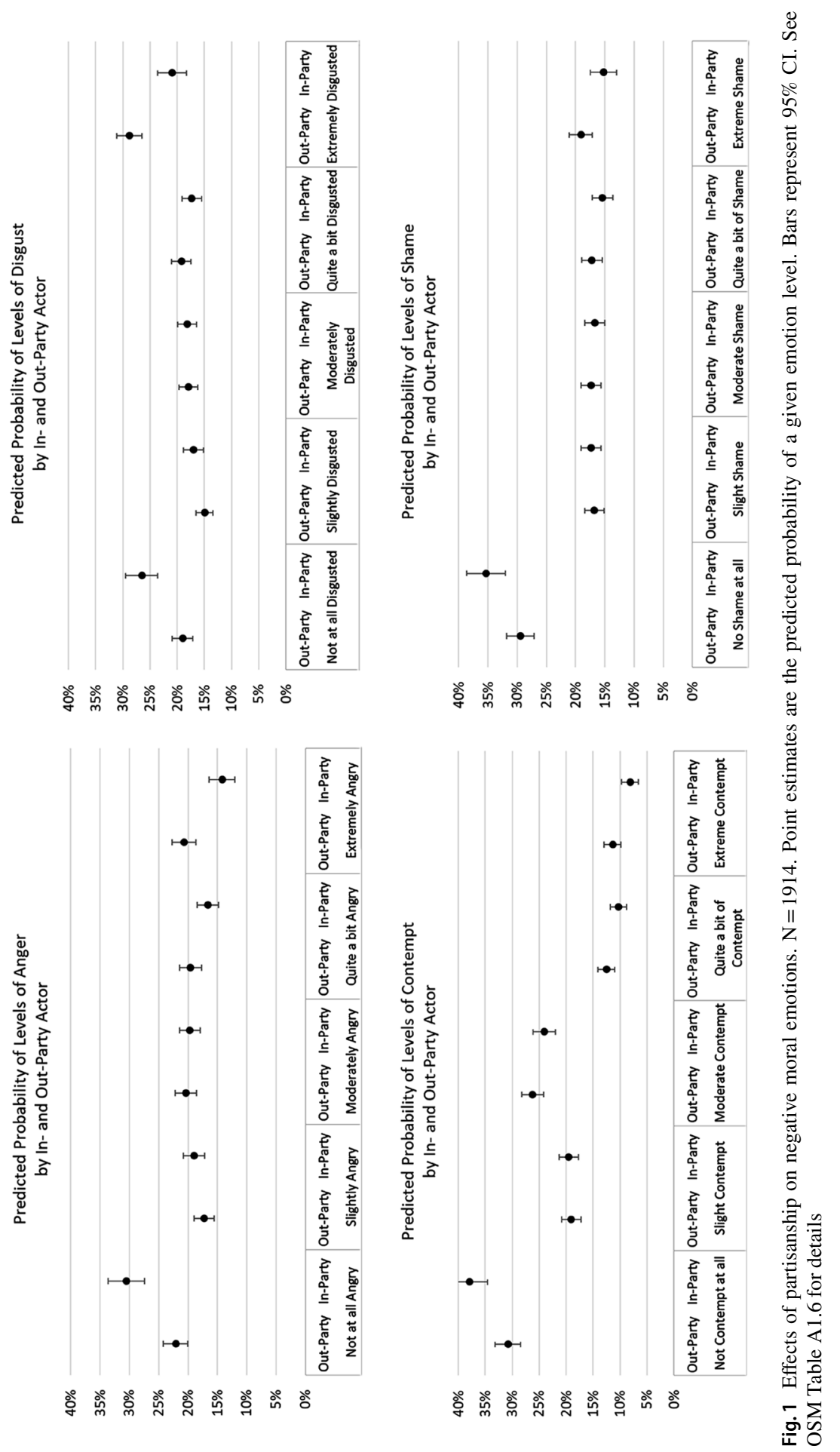




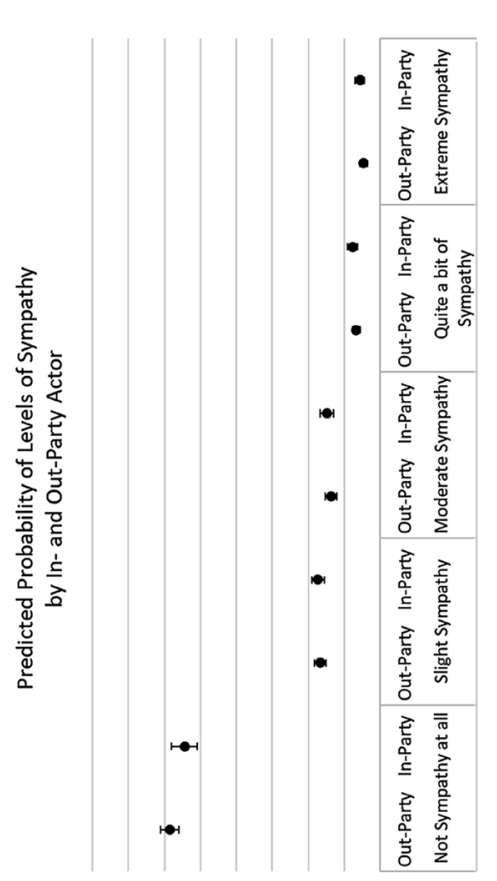

ڤั

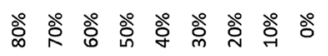

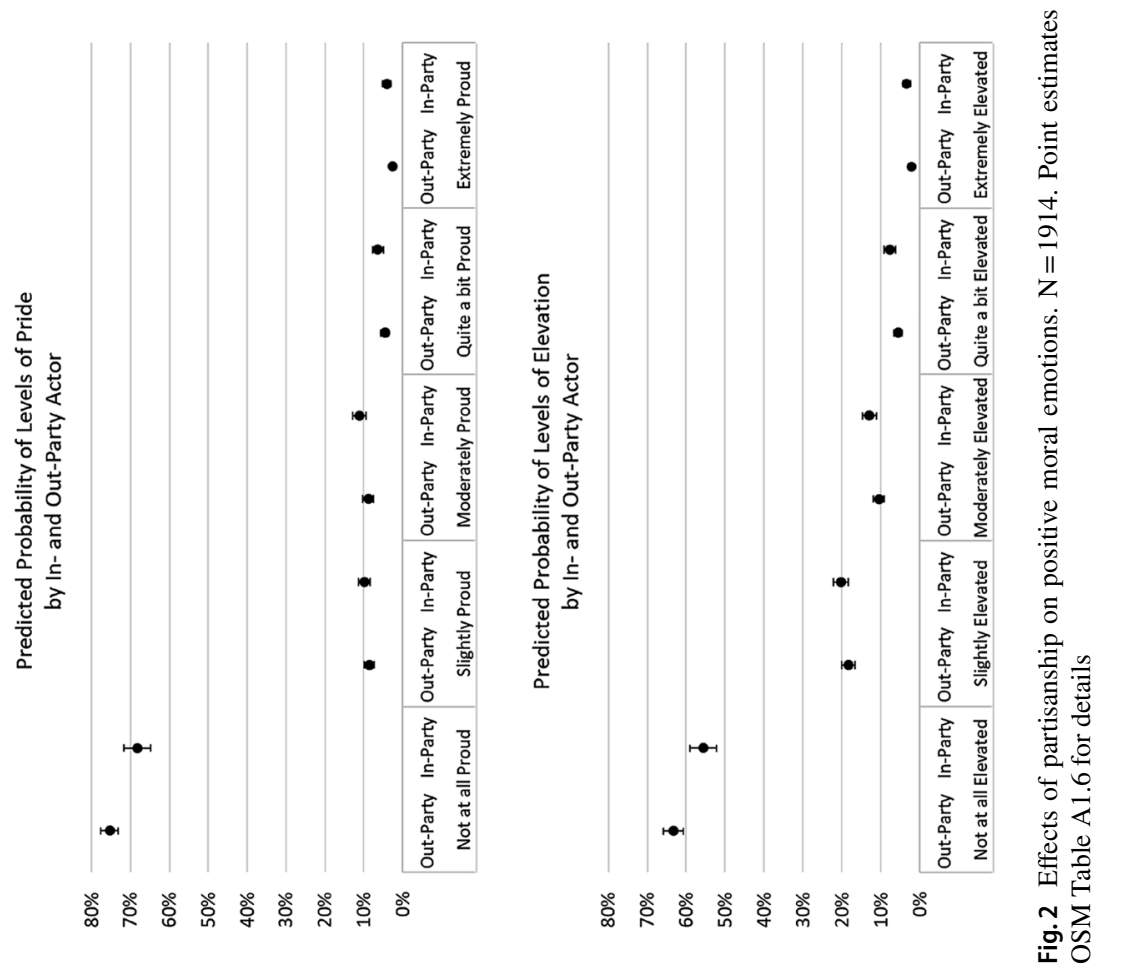




\section{Hypothesis 4: Party Identification Strength}

Having established that group identity conditions how voters respond to moral transgressions of politicians, we examine the effects of the strength of group (partisan) attachment. For this analysis, we consider only respondents with a partisan identity, dropping 308 independents who did not lean toward one of the parties. Starting with the models reported in Table 4, we add a measure of partisan strength, coded so that strong partisan $=1$, weak partisan $=2$, and leaning partisan $=3$. Studies of American voting behavior regularly show that "leaning" partisans are as likely to vote for their party in presidential elections as are strong partisans, while weak partisans are less likely than either of the other groups to do so. Accordingly, we enter partisan strength as a set of dummy variables to indicate the levels, as reported in Table 5. We interact the strength variable with the in-party variable to identify the correspondence between voter party strength and seeing an in-party actor commit a moral foundation violation.

Figures 3 and 4 present the mean predicted probabilities of moral violations by both partisan strength and in- or out-party politician. While these figures are complicated, the results clarify that much of the effect we find is specifically with strong partisans. Turning again to anger to illustrate the negative moral emotions (Fig. 3), the strong partisans show the greatest difference between responses to in- and outparty politicians. Only $17 \%$ express no anger at all to the out-party violator, while nearly $31 \%$ show no anger towards the in-party violator. Weak and leaning partisans show gaps as well, but the effects are less strong in both cases. Strong partisans are also more likely to express anger "quite a bit" or "extremely" when faced with an out-party violator compared to the in-party, while weak and leaning partisans are again not as responsive to partisan differences. The patterns for contempt and shame are similar, although a disgust response seems to be particularly visible for leaning partisans, who seem quite like strong partisans in this one case.

Since few respondents expressed positive moral emotions, the results in Fig. 4 are much like in Fig. 2, except that now we see clearly that it is strong partisans who show significant and substantive differences in positive moral emotions by in- and out-party politicians across all positive moral emotions. Weak and leaning partisans show few effects of the in- versus out-party nature of the vignettes. Strong partisans are much more likely to express some level of positive emotion (that is, not be in the no emotion at all category) compared to both weak and leaning partisans.

\section{Discussion}

This paper aims to answer three questions: (1) What moral emotions are activated by politician's moral transgressions?, (2) Does the strength of a voter's commitment to a particular moral foundation condition the moral emotional response to a violation of that foundation?, and (3) What role does partisanship play in influencing moral emotional responses to politician's moral transgressions? This experimental study finds no clear evidence that specific moral foundations are connected to 


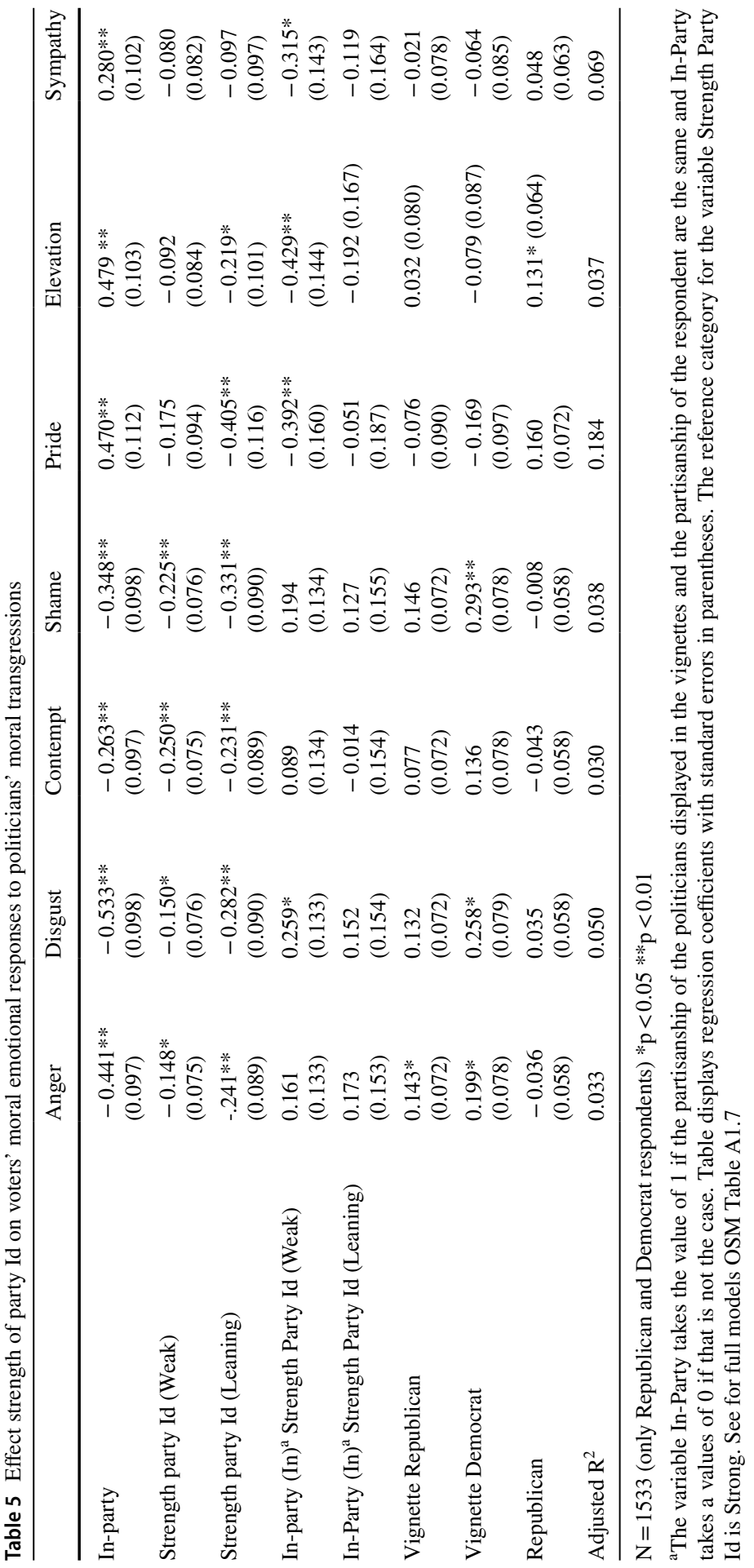




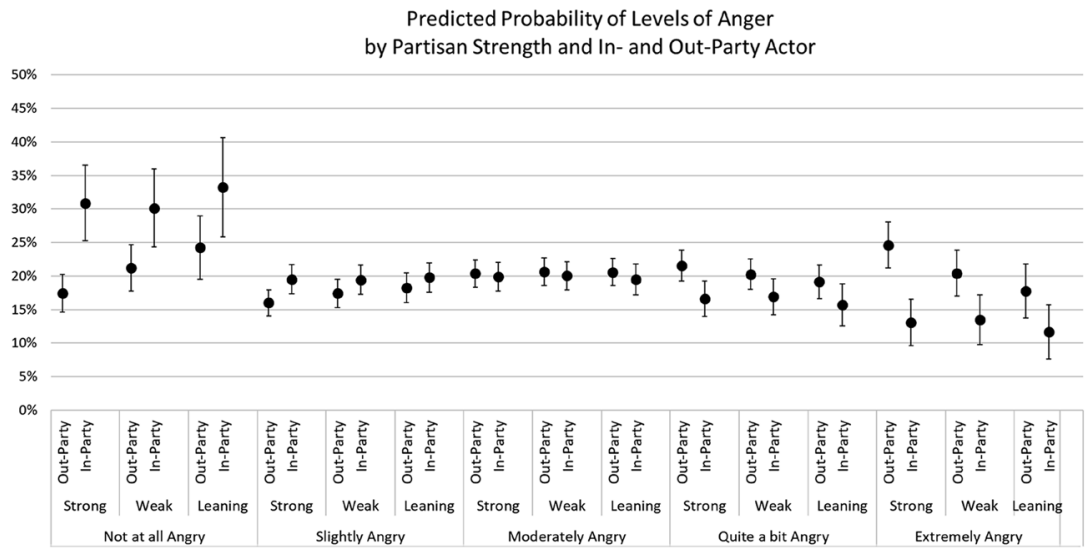

Predicted Probability of Levels of Disgust

by Partisan Strength and In- and Out-Party Actor

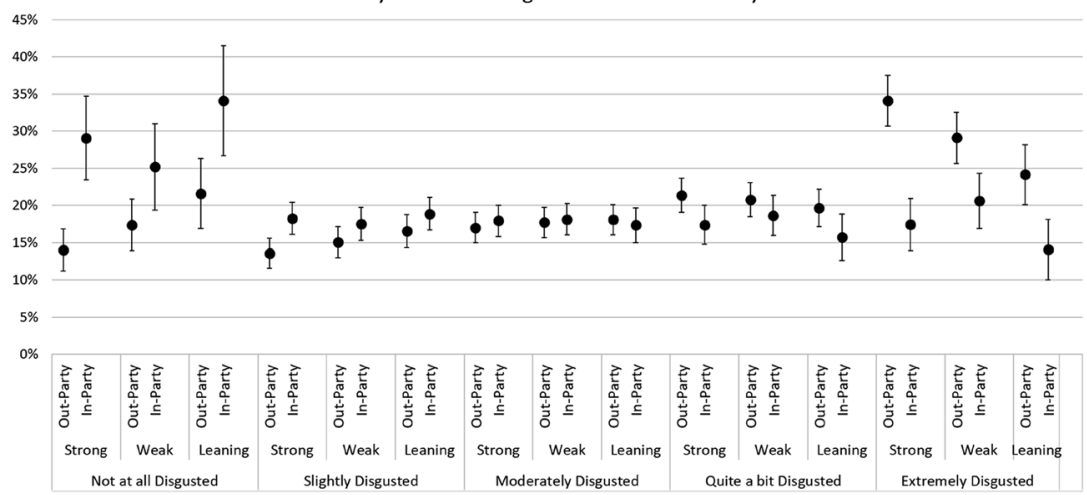

Predicted Probability of Levels of Contempt by Partisan Strength and In- and Out-Party Actor

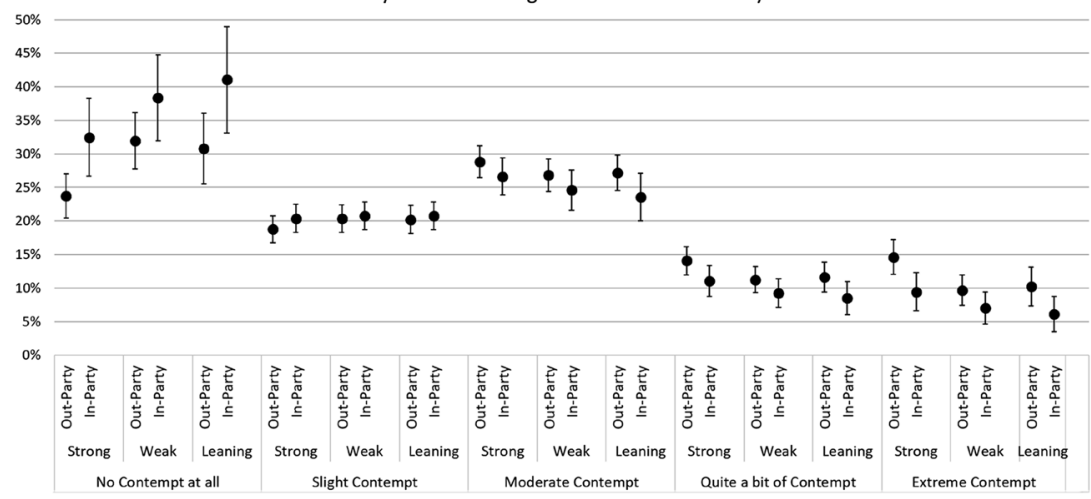

Fig. 3 Effect of partisanship and partisan strength on negative moral emotions. $\mathrm{N}=1533$. Point estimates are the predicted probability of a given emotion level. Bars represent 95\% CI. See OSM Table A1.10 for details 


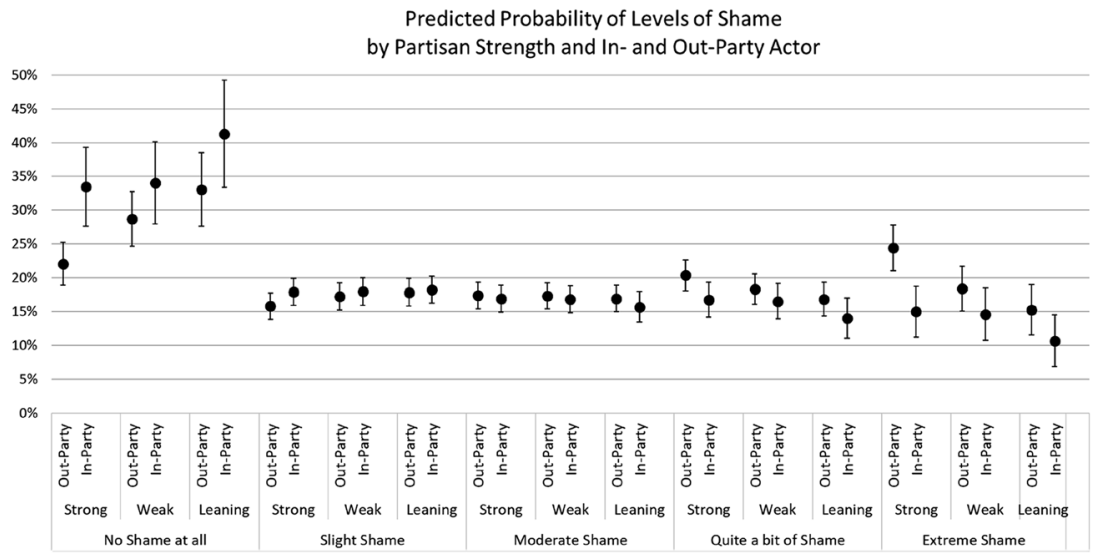

Fig. 3 (continued)

specific moral emotions as expected by MFT (Haidt, 2003; Haidt \& Joseph, 2004). Thus, we support Landmann and Hess's (2017) finding that emotional responses to violations of specific foundations are not strongly connected, at least in politics. We do find some evidence that personal moral commitments matter for moral emotional response to politicians' moral transgression more generally. Voters also differ in their moral emotional responses depending on their party identity and strength. When party identity is shared with the politician, anger, contempt, disgust and shame are all reduced while pride, elevation and sympathy are higher than when party identity is not shared. It is clear that partisanship acts as a group identity and perceptual lens affecting emotional responses to politicians' moral violations. Moreover, the particular finding that shame decreases comports with the argument that group members can become blind to moral violations.

These results should be of interest to scholars working on politicians' immoral behavior, political scandal, and group identity, as well as those who take a specific interest in MFT. Our findings add to existing challenges to MFT in two ways. First, the association between specific moral emotions and moral transgressions (Haidt, 2003; Haidt \& Joseph, 2004) is not found. Second, our findings challenge the innateness of MFT as have others (Ciuk, 2018; Smith et al., 2017), finding that the group identity (partisanship) is given more weight than voters' moral principles for these particular politically-oriented moral judgments. Partisanship in the U.S. is clearly a group identity (Mason, 2018) and acts like one here. Stronger group (partisan) identity limits the negative moral emotions associated with an in-group politician's immoral behavior. Although this article was intended as an attempt to understand how the violation of moral foundations by politicians influences voters as a precursor to scandal, rather than as a direct critique of MFT, our findings join the increasing challenges to MFT. These include studies that question the number of moral foundations [Iurino \& Saucier, 2020, see also the Theory of Dyadic Morality (Schein \& Gray 2015)], the innateness, modularity and stability of voters' moral foundations (Ciuk, 2018; Smith et al., 2017; Suhler \& Churchland, 2012), the causal 
Predicted Probability of Levels of Pride

by Partisan Strength and In- and Out-Party Actor

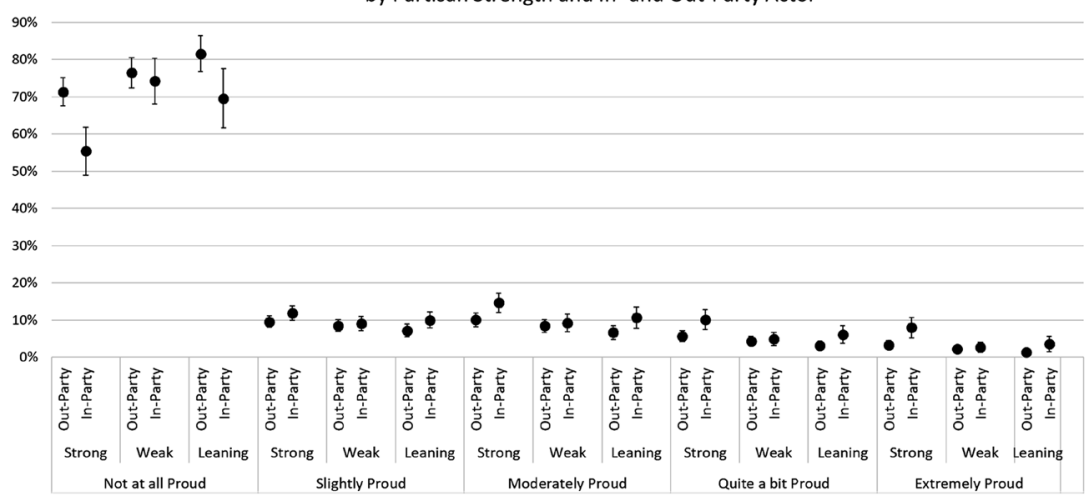

Predicted Probability of Levels of Elevation

by Partisan Strength and In- and Out-Party Actor

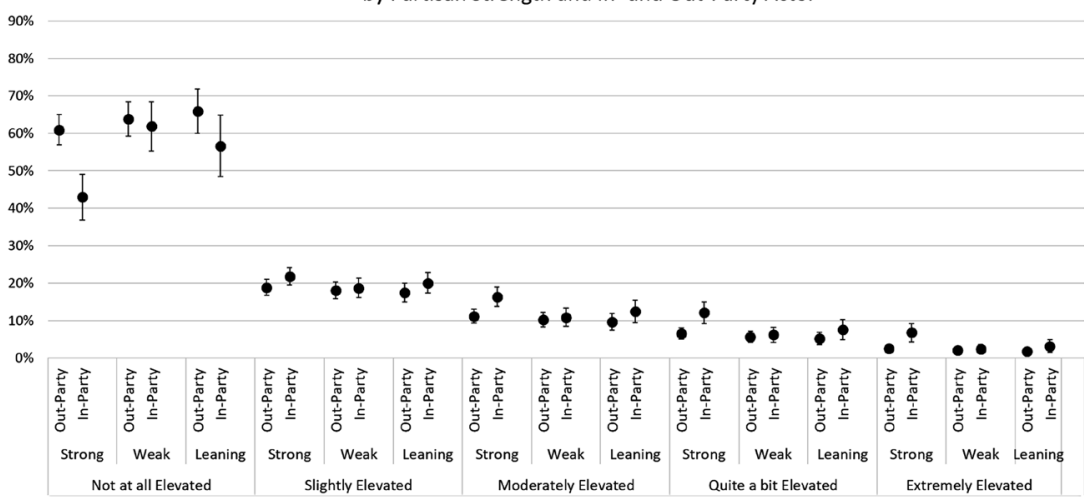

Predicted Probability of Levels of Sympathy

by Partisan Strength and In- and Out-Party Actor

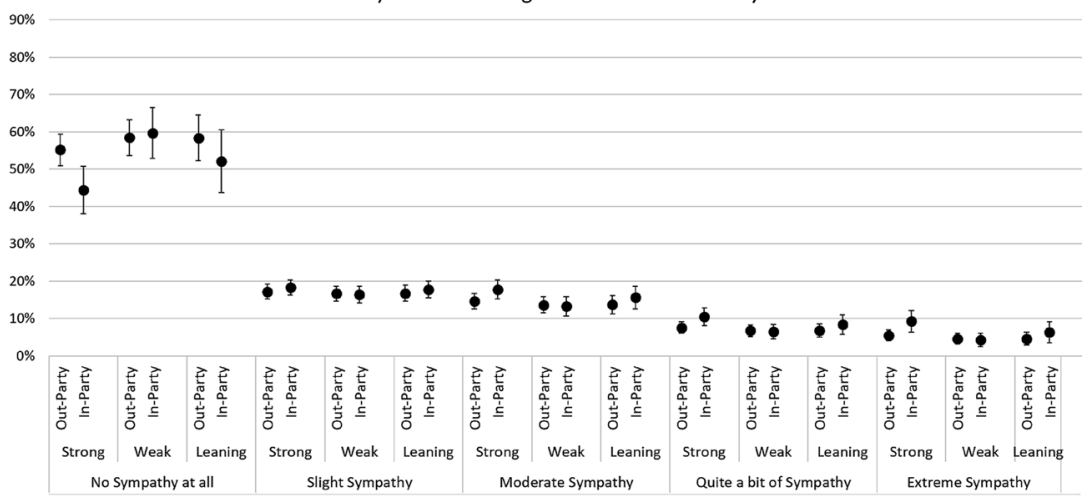

Fig. 4 Effect of partisanship and partisan strength on positive moral emotions. $N=1533$. Point estimates are the predicted probability of a given emotion level. Bars represent 95\% CI. See OSM Table A1.10 for details 
relationship between political ideology and moral foundations (Hatemi et al., 2019; Smith et al., 2017), the negligence of the social relational context in which (im) moral actions take place (Rai \& Fiske, 2011), and the measurement instrument used to gauge moral foundations (Tamul et al., 2020).

While we are not attempting to explain how moral transgressions by politicians become scandals, our results have some implications for both political actors and voters. First, it seems clear that partisan voters are willing to give own-party politicians a great deal of leeway in their behavior, even to the extent of violating the moral principles they may hold. This appears especially true of Republicans in our sample, while Democrats seem less willing to do so. In addition, and unsurprisingly given the negative partisanship well-established in the U.S., voters are much more condemning of out-party actors, even when they give a pass to their own side. This suggests that whether an action rises to the level of a scandal may depend to some extent on whether and when voters respond negatively to their own politicians. After all, the other side is always scandalous, so the identified negative responses to an out-party moral violation would not be cause for the media to highlight the transgression, unless own-party responses become negative as well (see the recent response by Democrats to sexual harassment claims against New York Governor Andrew Cuomo.) While our results suggest that in-party responses to moral violations are less likely to be as negative as out-party responses, these examples show negative responses are possible. Our findings that Republicans may be less negatively responsive to moral violations across vignettes may help explain not only many GOP supporter's willingness to ignore Donald Trump's moral violations, and to support Brett Kavanaugh despite the claims against him, but also why Democrats appear more likely in some cases to take on their own co-partisan's violations, as in the Hill and Franken cases noted in the introduction.

As with any study, our study has limitations. Given how we asked the emotions questions, we focused respondents on the violator more than the victim, limiting our findings for positive moral emotions. In a future study respondents should be asked their responses to both the perpetrator and victim of the moral violation. Another limitation is that the vignettes employed very specific actions. There is likely heterogeneity in people's responses to these actions, and by design, each study participant saw only one action representing one moral foundation. While we address this in our meaning components analysis, a design where participants responded to more than one violation might help tease out effects. However, in these article we are less interested in reactions to specific vignettes than we are in the larger story, that partisan identity is a powerful group identity that can lead to ignoring moral principles in the face of co-partisan actors as evidenced by less negative moral emotional response. Further, although vignettes were pre-tested, both the authority and sanctity vignettes were less powerful than we would have preferred; replication with other violations of these foundations would be useful.

In addition, this paper examines voters' moral emotional responses to politicians' moral transgressions and not political scandals as such. Consequently, the vignettes were not presented as media reports as would be useful if we had been examining scandals. We consider voters' responses to politicians' moral violations indicative of whether voters find these truly transgressive, which is a 
necessary condition for a moral transgression to develop into a scandal. Future work could look at voters' moral responses to political scandals as reported by the media by presenting politicians' moral transgressions embedded in a media report and measuring the effects of factors such as source credibility and motivated reasoning processes on voters' moral emotional responses.

Finally, this study was conducted following the 2016 U.S. presidential elections, which led to the election of a politician with frequent moral transgressions. It is not unthinkable that in a different time we might find differences with respect to the strength of overall responses to violations of moral foundations.

Nonetheless, this study provides key evidence on how moral emotions are influenced by partisan actors violating particular moral precepts and people's sense of what is right and wrong. We followed moral foundations theory in defining the principles that were violated, and in doing so we have added to the questions that surround MFT itself. While it is clear that in a partisan political context where a politician might violate their sense of what is morally right, voters are likely much less concerned about morality if the politician is a co-partisan. Thus, while Democrats might have fumed about Donald Trump's moral transgressions, his co-partisans were simply less likely to be upset, providing him (and other politicians) with a sort of cover that perhaps allows a surprising amount of leeway in behavior before it rises to the level of scandal.

Supplementary Information The online version contains supplementary material available at https://doi. org/10.1007/s11109-021-09749-z.

Acknowledgements We thank Cees van der Eijk for his methodological suggestions.

Funding The data collection was funded by a Nottingham Research Fellowship granted by the University of Nottingham.

Data Availability The data and code to replicate the results in this article are publicly available and can be found at: https://doi.org/10.7910/DVN/MO72A2.

Code Availability (software application or custom code) Analysis carried out in Stata, code is made available at: https://doi.org/10.7910/DVN/MO72A2.

\section{Declarations}

Conflict of interest All the authors declared that they have no conflict of interest.

Ethical Approval Approved by the University of Delaware Institutional Review Board.

Open Access This article is licensed under a Creative Commons Attribution 4.0 International License, which permits use, sharing, adaptation, distribution and reproduction in any medium or format, as long as you give appropriate credit to the original author(s) and the source, provide a link to the Creative Commons licence, and indicate if changes were made. The images or other third party material in this article are included in the article's Creative Commons licence, unless indicated otherwise in a credit line to the material. If material is not included in the article's Creative Commons licence and your intended use is not permitted by statutory regulation or exceeds the permitted use, you will need to obtain permission directly from the copyright holder. To view a copy of this licence, visit http://creativecommons.org/licen ses/by/4.0/. 


\section{References}

Algoe, S. B., \& Haidt, J. (2009). Witnessing excellence in action: The 'other-praising emotions of elevation, gratitude and admiration. Journal of Positive Psychology, 4, 105-127.

Bowler, S., \& Karp, J. S. (2004). Politicians, scandals, and trust in government. Political Behavior, $26,271$.

Campbell, A., Converse, P. E., Miller, W. E., \& Stokes, D. E. (1980). The American voter. University of Chicago Press.

Ciuk, D. J. (2018). Assessing the contextual stability of moral foundations: Evidence from a survey experiment. Research \& Politics. https://doi.org/10.1177/2053168018781748

Clifford, S., Iyengar, V., Cabeza, R., \& Sinnott-Armstrong, W. (2015). Moral foundations vignettes: A standardized stimulus database of scenarios based on moral foundations theory. Behavior Research Methods, 47, 1178-1198.

Doherty, D., Dowling, C. M., \& Miller, M. G. (2011). Are financial or moral scandals worse. It depends. P.S. Political Science \& Politics, 44(4), 749-757.

Eisenberg, N. (1986). Altruistic emotion, cognition, and behavior. Hillsdale, N.J: Erlbaum.

Emler, N. (2003). Morality and political orientations: An analysis of their relationship. European Review of Social Psychology, 13(1), 259-291. https://doi.org/10.1080/10463280240000082

Emler, N., Renwick, S., \& Malone, B. (1983). The relationship between moral reasoning and political orientation. Journal of Personality and Social Psychology, 45, 1073-1080.

Graham, J., Nosek, B. A., Haidt, J., Iyer, R., Koleva, S., \& Ditto, P. H. (2011). Mapping the moral domain. Journal of Personality and Social Psychology, 101, 366-385.

Haidt, J. (2001). The emotional dog and its rational tail: A social intuitionist approach to moral judgement. Psychological Review, 108, 814-834.

Haidt, J. (2003). The moral emotions. In R. J. Davidon, K. R. Scherer, \& H. H. Goldsmith (Eds.), Handbook of affective sciences (pp. 852-870). Oxford University Press.

Haidt, J., \& Graham, J. (2011). Mapping moral domain. Journal of Personality and Social Psychology, 101, 366-385.

Haidt,- J., \& Hersh, M. A. (2001). Sexual morality: The cultures and emotions of conservatives and liberals. Journal of Applied Social Psychology, 31(1), 191-221. https://doi.org/10.1111/j.1559-1816. 2001.tb02489.x.

Haidt, J., \& Joseph, C. (2004). How innately prepared intuitions generate culturally variable virtues. Daedalus, 133(4), 55-56.

Haidt, J., \& Joseph, C. (2011). How moral foundations theory succeeded in building on sand: A response to suhler and churchland. Journal of Cognitive Neuroscience, 23(9), 2117-2122. https://doi.org/10. 1162/jocn.2011.21638.

Halmburger, A., Rothmund, T., Schulte, M., \& Baumert, A. (2012). Psychological reactions to political scandals: Effects on emotions, trust, and need for punishment. Politische Psychologie-Journal of Political Psychology, 2, 30-51.

Halperin, E., \& Schori-Eyal, N. (2019). Moral emotions in political decision making. Oxford Research Encyclopedia of Politics. https://doi.org/10.1093/acrefore/9780190228637.013.922

Hatemi, P. K., Crabtree, C., \& Smith, K. B. (2019). Ideology justifies morality: Political beliefs predict moral foundations. American Journal of Political Science, 63(4), 788-806.

Imhoff, R., Bilewicz, M., \& Erb, H.-P. (2012). Collective regret versus collective guilt: Different emotional reactions to historical atrocities. European Journal of Social Psychology, 42(6), 729-742.

Iurino, K., \& Saucier, G. (2020). Testing measurement invariance of the moral foundations questionnaire across 27 countries. Assessment, 27(2), 365-372.

Iyer, A., Schmader, T., \& Lickel, B. (2007). Why individuals protest the perceived transgressions of their country: The role of anger, shame, and guilt. Personality and Social Psychology Bulletin, 33(4), 572-587.

Jiang, J., Kou, Y., Wang, F., Wu, Y., Li, Y., Li, Y., Yang, Y., Cao, H., Wu, Q., Jing, S., Jiang, B., Shen, L., Li, A., Li, Z., Gao, W., Chiu, C., Hong, Y., Hsu, S., Zhang, L., et al. (2011). Emotional reactions to scandals: When does moral character make a difference? Asian Journal of Social Psychology, 1, 207-216.

Landmann, H., \& Hess, U. (2017). Testing moral foundation theory: Are specific moral emotions elicited by specific moral transgressions? Journal of Moral Education. https://doi.org/10.1080/ 03057240.2017.1350569 
Lickel, B., Steele, R. R., \& Schmader, T. (2011). Group-based shame and guilt: Emerging directions in research. Social and Personality Psychology Compass, 5(3), 153-156.

Marcus, G. E., Neuman, W. R., \& MacKuen, M. (2000). Affective intelligence and political judgment. University of Chicago Press.

Mason, L. (2018). Uncivil agreement: How politics became our identity. University of Chicago Press.

Narvaez, D., Getz, I., Rest, J. R., \& Thoma, S. J. (1999). Individual moral judgment and cultural ideologies. Developmental Psychology, 35(2), 478.

Pagano, S. J., \& Huo, Y. J. (2007). The role of moral emotions in predicting support for political actions in post-war Iraq. Political Psychology, 28(2), 227-255.

Rai, T. S., \& Fiske, A. P. (2011). Moral psychology is relationship regulation: Moral motives for unity, hierarchy, equality, and proportionality. Psychological Review, 118(1), 57-75.

Redlawsk, D. P. (2002). Hot cognition or cool consideration? Testing the effects of motivated reasoning on political decision making. Journal of Politics, 64(4), 1021-1044.

Redlawsk, D. P. (Ed.). (2006). Feeling politics: Emotion in political information processing. Palgrave-Macmillan.

Redlawsk, D. P., \& Pierce, D. R. (2017). Emotions and voting. In K. Arzheimer, J. Evans, \& M. LewisBeck (Eds.), Sage handbook of electoral Behaviour (pp. 406-432). Sage.

Rothschild, Z. K., Landau, M. J., Molina, L. E., Branscombe, N. R., \& Sullivan, D. (2013). Displacing blame over the ingroup's harming of a disadvantaged group can fuel moral outrage at a third-party scapegoat. Journal of Experimental Social Psychology, 49(5), 898-906. https://doi.org/10.1016/j. jesp.2013.05.005.

Rozin, P., \& Lowery, L. (1999). The CAD triad hypothesis: A mapping between three moral emotions (contempt, anger, disgust) and three moral codes (community, autonomy, divinity). Journal of Personality and Social Psychology, 76, 574-586.

Schein, C., \& Gray, K. (2015). The unifying moral dyad. Personality and Social Psychology Bulletin, 41(8), 1147-1163. https://doi.org/10.1177/0146167215591501.

Schein, C., \& Gray, K. (2018). The theory of dyadic morality: Reinventing moral judgment by redefining harm. Personality and Social Psychology Review, 22(2), 32-70.

Schnall, S., Roper, J., \& Fessler, D. M. T. (2010). Elevation leads to altruistic behavior. Psychological Science, 21, 315-320.

Smith, E. R., \& Mackie, D. M. (2016). Group-level emotions. Current Opinion in Psychology, 11, 15-19. https://doi.org/10.1016/j.copsyc.2016.04.005

Smith, E. R., Seger, C. R., \& Mackie, D. M. (2007). Can emotions be truly group level? Evidence regarding four conceptual criteria. Journal of Personality and Social Psychology, 93(3), 431-446.

Smith, K. B., Alford, J. R., Hibbing, J. R., Martin, N. G., \& Hatemi, P. K. (2017). Intuitive ethics and political orientations: Testing moral foundations as a theory of political ideology. American Journal of Political Science, 61(2), 424-437.

Sparks, P., \& Durkin, K. (1987). Moral reasoning and political orientation: The context sensitivity of individual rights and democratic principles. Journal of Personality and Social Psychology, 52(5), 931.

Suhler, C. L., \& Churchland, P. (2012). Can innate, modular 'foundations' explain morality? Challenges for Haidt's moral foundation theory. Journal of Cognitive Neuroscience, 23(9), 2103-2116.

Taber, C. S., \& Lodge, M. (2006). Motivated skepticism in the evaluation of political beliefs. American Journal of Political Science, 50(3), 755-769.

Tamul, D., Elson, M., Ivory, J. D., Hotter, J. C., Lanier, M., Wolf, J., \& Martínez-Carrillo, N. I. (2020, April 7). Moral foundations' methodological foundations: A systematic analysis of reliability in research using the moral foundations questionnaire.https://doi.org/10.31234/osf.io/shcgv

Tangney, J. P., Stuewig, J., \& Mashek, D. J. (2007). Moral emotions and moral behaviour. Annual Review of Psychology, 58, 345-372.

Thompson, J. B. (2000). Political scandal: Power and visibility in the media age. Polity Press.

Von Sikorksi, C. (2018). The aftermath of political scandal: A meta-analysis. International Journal of Communication, 12, 3109-3133.

Vonnahme, B. M. (2014). Surviving scandal: An exploration of the immediate and lasting effects of scandal on candidate evaluation. Social Science Quarterly, 95(5), 1308-1321.

Walter, A. S., \& Redlawsk, D. (2019). Voters' partisan responses to politicians' immoral behaviour. Political Psychology. https://doi.org/10.1111/pops.12582 
Zajonc, R. B. (1980). Feeling and thinking: Preferences need no inferences. American Psychologist, 35, $151-175$.

Publisher's Note Springer Nature remains neutral with regard to jurisdictional claims in published maps and institutional affiliations. 